\title{
Use of autologous bone marrow stem cell implantation for osteonecrosis of the knee in sickle cell disease: a preliminary report
}

\author{
Gildasio Daltro1, Bruno Adelmo Franco', Thiago Batista Faleiro', Davi Araujo Veiga Rosário', Paula Braga Daltro², \\ Roberto Meyer ${ }^{2}$ and Vitor Fortuna ${ }^{2^{*}}$
}

\begin{abstract}
Background: The purpose of our study was to evaluate safety, feasibility and clinical results of bone marrow mononuclear cell (BMC) implantation for early-stage osteonecrosis of the knee (OK) secondary to sickle cell disease.

Methods: Thirty-three SCD patients (45 knees) with OK treated with BMC implantation in the osteonecrotic lesion were clinically and functionally evaluated through the American Knee Society Clinical Score (KSS), Knee Functional Score (KFS) and Numeric Rating Scale (NRS) pain score. MRI and radiographic examinations of the knee were assessed during a period of five years after intervention.
\end{abstract}

Results: No complications or serious adverse event were associated with BMC implantation. From preoperative assessment to the latest follow-up, there was a significant $(p<0.001)$ improvement of clinical KSS $(64.3 \pm 9.7$, range: $45-$ 80 and $2.2 \pm 4.1$, range: $84-100$, respectively), KFS ( $44.5 \pm 8.0$, range: $30-55$ and $91.6 \pm 5.8$, range: $80-100$, respectively) and reduction of NRS pain score (6.7 \pm 1.2 , range: $4-9$ and $3.4 \pm 1.0$, range: $2-5$, respectively). In total, $87 \%$ of patients (29/33) consistently experienced improvements in joint function and activity level as compared to preoperative score. No patient had additional surgery following BMC implantation. Radiographic assessment showed joint preservation and no progression to subchondral collapse at most recent follow-up.

Conclusions: The technique of BMC implantation is a promising, relatively simple and safe procedure for OK in SCD patients. Larger and long-term controlled trials are needed to support its clinical effectiveness.

Trial registration: ClinicalTrials.gov NCT02448121. Retrospectively registered 19 May 2015.

Keywords: Osteonecrosis, Avascular necrosis, Knee, Sickle cell disease, Joint preserving surgery, Cell implantation

\section{Background}

Osteonecrosis of the knee $(\mathrm{OK})$ secondary to sickle cell disease (SCD) is a debilitating disorder that may progress to subchondral collapse and end-stage arthritis of the knee at an early age. Intravascular erythrocyte sickling and vaso-occlusion of microcirculation lead to ischemic death and necrosis of the constituents of the bone and marrow. In its early stage, the overlaying articular cartilage is intact, however, the changes in the subchondral bone may rapidly progress to structural collapse, chronic pain and joint destruction [1-3]. Advanced OK-SCD eventually requires

\footnotetext{
*Correspondence: vfort@ufba.br; vitor.fortuna@pq.cnpq.br

${ }^{2}$ Health Science Institute, Federal University of Bahia, Av. Reitor Miguel

Calmon, s/n, Vale do Canela, Salvador, BA 40110-100, Brazil

Full list of author information is available at the end of the article
}

knee arthroplasty, which is associated with increased risk of adverse outcome and higher revision rates in sickle cell disease patients [4]. For these reason, the early treatment is very important.

OK-SCD is usually part of a multifocal disease, and the knee is a particularly vulnerable joint in sickle cell disease. There have been a limited number of OK-SCD case reports and a high occurrence of osteonecrosis of the knee in asymptomatic patients $[2,5]$, therefore the exact occurrence of $\mathrm{OK}$ in sickle cell disease patients remains unclear. Flouzat-Lachaniete et al. [6] reported in a large study that $34 \%$ of SCD patients diagnosed with multifocal osteonecrosis had involvement of the knee. They also observed an annual incidence rate of 3.6 cases per

(c) The Author(s). 2018 Open Access This article is distributed under the terms of the Creative Commons Attribution 4.0 International License (http://creativecommons.org/licenses/by/4.0/), which permits unrestricted use, distribution, and reproduction in any medium, provided you give appropriate credit to the original author(s) and the source, provide a link to the Creative Commons license, and indicate if changes were made. The Creative Commons Public Domain Dedication waiver (http://creativecommons.org/publicdomain/zero/1.0/) applies to the data made available in this article, unless otherwise stated. 
100 patients, which makes joint-preserving techniques important to initially attempt.

Treatment options for osteonecrosis of the knee in SCD patients are limited. For symptomatic patients at an early stage, many conservative procedures are used to enable knee preservation instead of replacing it [7]. However, the efficacy of these joint-preserving techniques, including core decompression or debridement of the osteonecrotic lesion, has been controversial in SCD and many patients still progress to advanced osteonecrosis $[8-10]$. Therefore, even if positive results are obtained, the treatment of the OK-SCD continues to be a daunting problem for orthopedic surgeons.

Cell therapy with autologous implantation of concentrated bone-marrow mononuclear cells (BMC) has been used successfully for treatment of hip osteonecrosis $[11,12]$. Although no reports exist on the implantation of BMC in the knee in SCD patients, several authors described that BMC implantation can significantly decrease the pain and other joint symptoms caused by osteonecrosis and delay, or avoid the progress of this disease toward higher osteonecrotic stages [13, 14]. The rationale for the use of cell therapy for osteonecrosis in sickle cell disease patients relies on the presence of bone marrow-derived mesenchymal stromal cells (MSCs) and endothelial progenitors cells (EPCs) in BMC, which may enhance the mechanism of blood vessel formation and improve tissue repair [12, 15]. Other nucleated cells (macrophages, T cells, B cells, dendritic cells, natural killer cells and neutrophils) are also present in BMC and once introduced into the osteonecrotic lesion may help improve pain and function [13-15]. After encouraging results were obtained in the hip, the same technique has been transferred to the knee joint in sickle cell disease patients.

In this prospective pilot study we aimed to evaluate safety, feasibility, clinical and radiological results after minimally invasive implantation of autologous bone marrow mononuclear cell (BMC) in OK lesions secondary to sickle cell disease.

\section{Methods}

\section{Study participants and design}

The National Committee of Ethics in Research (CONEP) and the Brazilian Ministry of Public Health approved this study protocol. All patients provided full informed consent before enrollment in the study.

Between December 2010 and December 2016, we reviewed the prospectively collected records of sickle cell disease patients who had been evaluated and treated for symptomatic hip osteonecrosis. Of the 243 SCD cases receiving treatment in the orthopedic department at our institution, fifty-one patients were diagnosed as having early-stage knee osteonecrosis secondary to sickle cell disease. We excluded 2 patients in early stages knee osteonecrosis without pain. We excluded 4 patients who had undergone hip replacement surgery. We also excluded a further seven patients because of advanced knee osteonecrosis and five patients referring hip pain diffusing to lower limb. We evaluated the remaining patients and 33 patients (45 knees) were included. All our patients presented with painful symptoms and the knee was the most symptomatic joint at the time of enrollment. At least one year after the treatment of foregoing hip osteonecrosis was required to enroll in this openlabel, prospective study. Physically active patients underwent clinical examination and had radiographic and magnetic resonance imaging (MRI) for both knees regardless of whether the knee was symptomatic. We identified patients with early-stage (stage I or II) knee osteonecrosis based on the Modified Ficat and Arlet staging system adapted for the knee [16-18] with characteristic MRI findings [19]. This radiographic classification staging system defined stage-I disease as knees with no abnormality. Stage-II disease have cystic or osteosclerotic lesions, or both, with a normal contour of the distal part of the femur or the proximal part of the tibia, or both, and with no subchondral fracture or flattening of the articular surface. Stage-III knees have flattening of the weightbearing contour of the condyle, or oval radiolucency in the subchondral area and Stage-IV knees have narrowing of the joint space with secondary osteoarthritic changes. The medial and lateral femoral condyles and the medial and lateral tibial plateaus were evaluated separately with use of this system (Table 1).

Inclusion criteria consisted of the following: (1) diagnosis of knee osteonecrosis stages 1 or 2 (pre-collapse); (2) presence of symptomatic, insidious and progressive pain; (3) availability of 1 - and 5-year follow-up assessments. Exclusion criteria were (1) an age younger than 18 years or older than 55 years; (2) radiologic diagnosis of advanced knee osteonecrosis (stage III or IV); (3) comorbidities with general medical conditions (e.g., diabetes or rheumatoid arthritis); (4) previous knee surgery or presence of total hip replacement on affected or contralateral limb; (5) presence of at least one of the following conditions: Intraarticular corticosteroid injection in the affected knee, diffuse or degenerative osteoarthritis, infection, knee trauma, fracture or deformity involving the knee, neoplastic disease, inflammatory arthritis, immunosuppressive therapy, alcoholism or nicotine abuse.

A total of twenty female $(60.6 \%)$ and thirteen $(39.4 \%)$ male were enrolled. The genotypes of the patients enrolled included $48.5 \%$ patients who are homozygous for the sickle-cell gene (hemoglobin SS, HBSS) and 51.5\% of patients with heterozygous combination with haemoglobin (hemoglobin SC, HBSC). Their mean age at the time of surgery was 28.4 years (range 18-42), and the mean 
Table 1 Staging system for Osteonecrosis of the Knee (OK) in Sickle Cell Disease [17]

\begin{tabular}{ll}
\hline Stage & Radiological findings \\
\hline 1 & Normal appearance, accompanied by pain \\
2 & $\begin{array}{l}\text { Cystic or osteosclerotic lesions, or both, with a normal contour of the distal part of the femur or the proximal part of the tibia, or both, and } \\
\text { with no subchondral flattening of the articular surface. }\end{array}$ \\
3 & $\begin{array}{l}\text { Presence of crescent sign. Flattening of the condyle or collapse of the subchondral bone plate with formation of a calcified plate and a clear } \\
\text { sclerotic halo. Slightly narrowed joint space. }\end{array}$ \\
4 & Osteoarthritic changes, such as spur formation and osteosclerosis, with a shallow concave articular surface at the osteonecrotic region
\end{tabular}

duration of symptoms before surgery was 6 months. The details and laboratory characteristics of the study subjects are shown in Table 2.

\section{Bone marrow mononuclear cell (BMC) concentrate}

Bone marrow aspirate $(\sim 120 \mathrm{~mL})$ was harvested, under general anesthesia, from the patients' anterior iliac crest according previously described [12]. The depth and angle of the trocar was changed after each $5 \mathrm{ml}$ of aspirated material to avoid hemodilution. The aspirated bone marrow was processed directly in the operating room, by removing most of the erythrocytes and plasma. A cell separator (SEPAX, Biosafe, Switzerland) consisting of a centrifuge and a disposable double chamber device, provided approximately $40 \mathrm{~mL}$ (fixed volume) of concentrate containing bone marrow mononuclear cells $(B M C)$ after sixty minutes of multiple centrifugation, in

Table 2 Patient Demographic Characteristics at Baseline

\begin{tabular}{|c|c|}
\hline Parameter & Value \\
\hline $\mathrm{N}^{\circ}$ of patients studies & 33 \\
\hline Age (years), mean $\S$ & $28.4(18-42)$ \\
\hline Men, n (\%) & 39.4 \\
\hline Hematocrit (\%) $\pm S D$ & 21.9 \\
\hline Total hemoglobin $(\mathrm{g} / \mathrm{l})$ & 6.9 \\
\hline \multicolumn{2}{|l|}{ Genotype $\left(\mathrm{N}^{\circ}\right)$} \\
\hline $\mathrm{HbSS}$ & 16 \\
\hline $\mathrm{HbSC}$ & 17 \\
\hline $\mathrm{N}^{\circ}$ of patients with bilateral involvement & $36.4 \%(12 / 33)$ \\
\hline$N^{\circ}$ of knees enrolled & 45 \\
\hline \multicolumn{2}{|l|}{ Staging } \\
\hline Stage 1 & $48.5 \%(21 / 45)$ \\
\hline Stage 2 & $51.5 \%(24 / 45)$ \\
\hline \multicolumn{2}{|l|}{ Localization } \\
\hline Medial femoral condyle & $42.3 \%(19 / 45)$ \\
\hline Lateral femoral condyle & $24.4 \%(11 / 45)$ \\
\hline Medial tibial plateau & $20.0 \%(9 / 45)$ \\
\hline Lateral tibial plateau & $13.3 \%(6 / 45)$ \\
\hline
\end{tabular}

accordance with the manufacturer's recommendations. The BMC was transferred to a $20 \mathrm{~mL}$ syringe for injection into the osteonecrotic lesion. This procedure required around $2 \mathrm{~h}$ from bone marrow collection, extraction, processing and injection into the patient. A small fraction of the BMC was separated for flow cytometry, cell viability and microbiological assays.

\section{Operative technique}

With the patient in the supine position, a 3-mm marrow-needle was inserted in the center of the osteonecrotic area under fluoroscopic guidance using a minimally invasive procedure. The BMC implantation was done through a percutaneous approach when the needle was advanced until it reached the lesion in the epiphyseal region. Each patient received the BMC implantation through a single injection puncture. The needle was directed to either the medial or lateral condylar lesion under fluoroscopic guidance and the $\mathrm{BMC}$ was injected at once into the osteonecrotic lesion. Coexisting injuries were treated concurrently as needed. Bleeding or leakage of the infused BMC fraction was controlled.

\section{BMC viability and flow cytometry analysis}

The viability of infused cells, as determined by Trypan blue exclusion, was above $95 \%$. The number of nucleated cells in each patient sample was counted with an automatic hemocytometer. Each sample was counted three times and the average calculated. The total nucleated cell count for injection was determined by multiplying the dilution factor and the final volume of the sample.

BMC were also analyzed by flow cytometry. The cell membrane antigens analyzed included those proposed by the ISHAGE protocol: anti-CD34-PE (BD Bioscience, NJ, USA), anti-CD45-FITC (Becton Dickinson, CA, USA) and their appropriate isotype-matched IgGs. For analysis, $5 \times 10^{5}$ events were acquired and scored with a FACS Calibur analyzer (Becton Dickinson). Data were processed using the Macintosh CELLQuest software program (Becton Dickinson). CFU-F assays were done according to previously described [12]. 


\section{Clinical and radiographic examination}

All patients were clinically evaluated before surgery, and at regular intervals after BMC implantation, by two independent examiners. Evaluation was scheduled at one month, one year and yearly thereafter.

The data were collected prospectively and included demographic, peri-operative data, and clinical outcome. Objective clinical and functional assessment was performed in a nonblinded manner by the treating surgeon using the American Knee Society scoring system, a dual rating system that comprises the Knee Society Score (KSS) and Knee Functional Score (KFS). The KSS includes pain, range of motion, flexion contractures, extension lag, alignment, and stability in the anteroposterior and mediolateral plane. The KFS includes the level of activity, walking/stair climbing and use of assistive devices [20, 21]. The results were both classified based on a 100-point scale as excellent (score, 85-100), good (score, 70-84), fair (score, 60-69), and poor (score, $\leq 59$ ).

The patients were questioned concerning their pain, the type of onset (sudden or progressive), the main areas of pain together with the spread areas, the presence of limp, the history of a triggering event, and the duration of symptoms. Patients with moderate to severe hip pain, diffusing to lower limb were not included in the study. Patients were prospectively analyzed with standardized numeric rating scale (NRS) to evaluate the knee pain severity (where "0" represented no pain, and "10" represented the maximum possible or unbearable pain) and a NRS Satisfaction subscale to assess patient satisfaction with the surgery [22]. The distribution of knee pain was not significantly different when patients had foregoing treatment of hip osteonecrosis. Failure was defined as the need of a new surgical procedure to treat persisting pain or effusion in the previously operated knee.

Radiographs and MRIs of the affected knee were taken at presentation. At the most recent follow-up, radiographic assessment included evaluation for radiolucent lines and was performed using standing weight-bearing anteroposterior and lateral radiographs of the knee. Postoperative MRIs were not performed.

\section{Statistical analysis}

Continuous data were described as mean \pm SD and categorical variables as mode and range. The distribution of continuous data was determined using the KolmogorovSmirnov test. Comparisons between the pre-treatment and follow-up scores were made using Student's t-test for independent continuous variables or the MannWhitney U-test and Wilcoxon sign-rank test when the assumption of normality was not realized. To assess the correlation between clinical findings (KSS / KFS) and categorical data, the differences between pre- and posttreatment values (change in KSS and change in KFS) were calculated. Then, continuous and categorical data were examined using the Pearson's Chi-Square Test. The independent variables explored were gender, stage of the osteonecrosis, genotype of the sickle cell disease and presence of bilateral knee osteonecrosis. Statistical significance was defined as $P<0.05$.

\section{Results}

At presentation, 21 patients (63.6\%) had unilateral osteonecrosis (the right knee was affected in 9 cases and the left knee in 12 cases) and 12 patients (36.4\%) had bilateral osteonecrosis. OK was stage I in 16 patients (21 knees) and stage II in 17 patients ( 24 knees), according to classification system (Table 1). Osteonecrotic lesions were predominantly located in the medial femoral condyle (19 knees, i.e. $42.3 \%$ ) followed by the lateral femoral condyle (Table 2). Examination of preoperative MRI consistently revealed subchondral areas of early-stage osteonecrosis and diffuse bone marrow edema (Figs. 1 and 2).

Overall, the interventional procedure was well tolerated by SCD patients, with no complications or serious adverse event (deaths, hematoma, nerve injury and others). Only four episodes of small adverse events (site infection following cell injection, and transient local pain) were noted. No serious adverse events or failure led to treatment discontinuation or study termination. The mean observation follow up period was 27.3 months (range: 12-60).

All SCD patients suffered from symptomatic knee joint and limitation of knee motion at the time of enrollment. Pre-operative KSS was poor in $8 / 33$ patients $(24.2 \%)$ and fair in $17 / 33$ patients $(51.6 \%)$ whereas KFS was poor in $31 / 33$ patients (94\%) and fair in $2 / 33$ patients $(6 \%)$ (Table 3). After the percutaneous BMC implantation improvements were observed in both KSS and KFS rating systems compared to the preoperative state. After surgery, 97\% (32 out of 33 patients) had excellent outcome in KSS score whereas the KFS score was good in three patients (9\%), and excellent in the remaining thirty patients (91\%). The mean KSS (and standard deviation) was $64.3 \pm 9.7$ (range: $45-80$ ) before surgery and $92.2 \pm$ 4.1 (range: $84-100$ ) at a mean of $27.3 \pm 13.8$ months $(p<0.001)$, while the KFS was $44.5 \pm 8.0$ (range: $30-55$ ) before surgery and $91.6 \pm 5.8$ (range: $80-100$ ) at a mean of $27.3 \pm 13.8$ months $(\mathrm{p}<0.001)$ (Fig. 3a, b) (Table 3). KSS and KFS evaluation preoperatively and at the time of follow-up showed clinical improvement was maintained over time (Fig. 4a, b). However, no correlation was seen between change in clinical scores (changes in KSS or KFS) and gender $(p=0.02 ; 0.008)$, stage of the osteonecrosis $(p=0.26 ; 0.11)$, genotype of the sickle cell disease $(p=0.35 ; 0.12)$, and presence of bilateral knee osteonecrosis $(0.015 ; 0.10)$, respectively. 


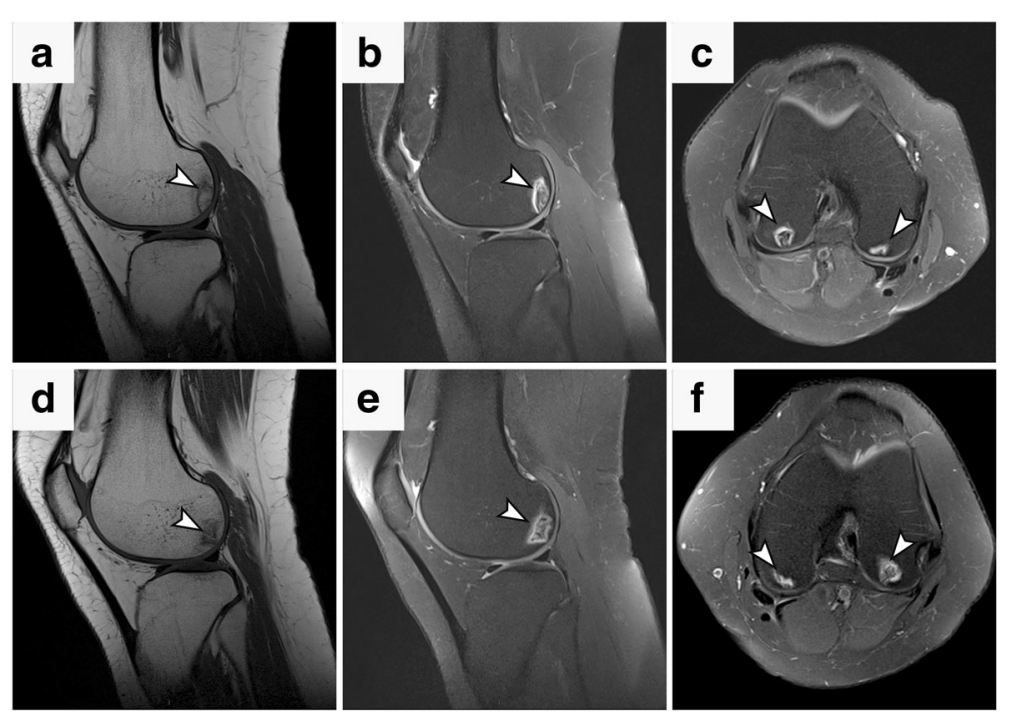

Fig. 1 Osteonecrosis of the knees in a 33-year-old woman with SCD. (a - f) T1-weighted (a, $\mathbf{d}$ - sagittal) and proton density fat-suppressed (b, e - sagittal; $\mathbf{c}, \mathbf{f}$ - axial) sequences demonstrates subchondral lesions (arrowheads) on the posterior portions of the right (a, $\mathbf{b}, \mathbf{c})$ and left $(\mathbf{d}, \mathbf{e}$, f) condyles. The osteonecrotic lesion is surrounded by border appearing hypo/hyperintense (double rim sign) (b, c, e, $\mathbf{f}$ ) indicating granulation and sclerosis respectively (arrowheads). MRI scans before surgery shows subchondral lesions representing early osteonecrosis in Ficat II stage. Both knees were treated with BMC implantation

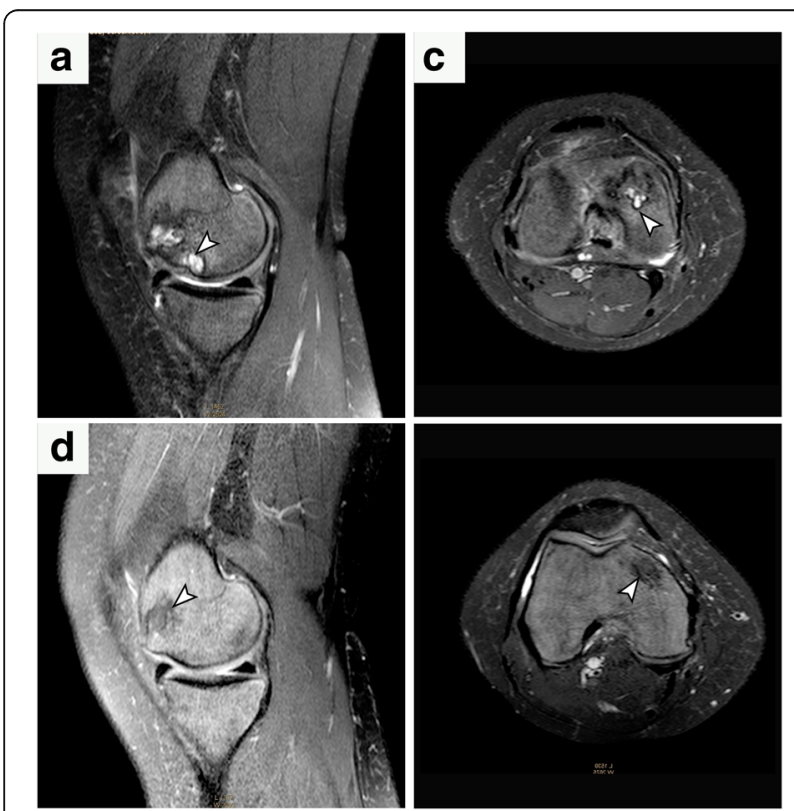

Fig. 2 Bilateral osteonecrosis of the knees in a symptomatic 39-year-old woman with SCD. (a - d) Proton density fat-suppressed (a, c - sagittal) and T2-weighted (b, d - axial) sequences demonstrate subchondral abnormalities (arrowheads) located in the medial femoral condyle (weight bearing zones). Subcortical high-intensity inner line $(\mathbf{a}-\mathbf{c})$ representing granulation tissue. MRI scans before surgery shows osteonecrotic lesion in Ficat I and II on left and right knees, respectively. Both knees were treated with BMC implantation
At beginning, all 33 patients had moderate or severe pain usually localized, occurring both at motion, weight-bearing and at rest, causing significant functional impairment in all cases. After BMC implantation, pain decreased was observed in $87.8 \%$ (29/33 patients) and remained unchanged only in $4(12.2 \%)$ patients. The mean NRS pain score decreased from $6.7 \pm 1.2$ (mode: 7 ; range: $4-9$ ) to $4.5 \pm 0.8$ (mode: 4 ; range: $2-5)$ after BMC implantation $(p<0.001)$ (Fig. 3c) (Table 3). Among 33 patients, 29 (87\%) were highly

Table 3 Overall Results Based on the American Knee Society Scoring System

\begin{tabular}{llll}
\hline Parameter & Preoperative & Postoperative & $P$ value \\
\hline Pain Score & $6.7 \pm 1.2$ & $3.4 \pm 1.0$ & $0.001^{*}$ \\
Knee Score (KSS) & & & \\
Average Score & $64.3 \pm 9.6$ & $92.2 \pm 4.2$ & $0.001^{\dagger}$ \\
Excellent & 0 & $97 \%(32 / 33)$ & \\
Good & $24.2 \%(8 / 33)$ & $3 \%(1 / 33)$ & \\
Fair & $51.6 \%(17 / 33)$ & 0 & $0.001^{\dagger}$ \\
Poor & $24.2 \%(8 / 33)$ & 0 & \\
Function score (KSS) & & & \\
Average Score & $44.5 \pm 8.0$ & $91.6 \pm 5.7$ & \\
Excellent & 0 & $91 \%(30 / 33)$ & \\
Good & 0 & $9.0 \%(3 / 33)$ & \\
Fair & $6 \%(2 / 33)$ & 0 & \\
Poor & $94 \%(31 / 33)$ & 0 & \\
\hline
\end{tabular}

Values are presented as mean \pm standard deviation KSS: Knee Society score

*Wilcoxon signed-rank test. †Paired t-test 


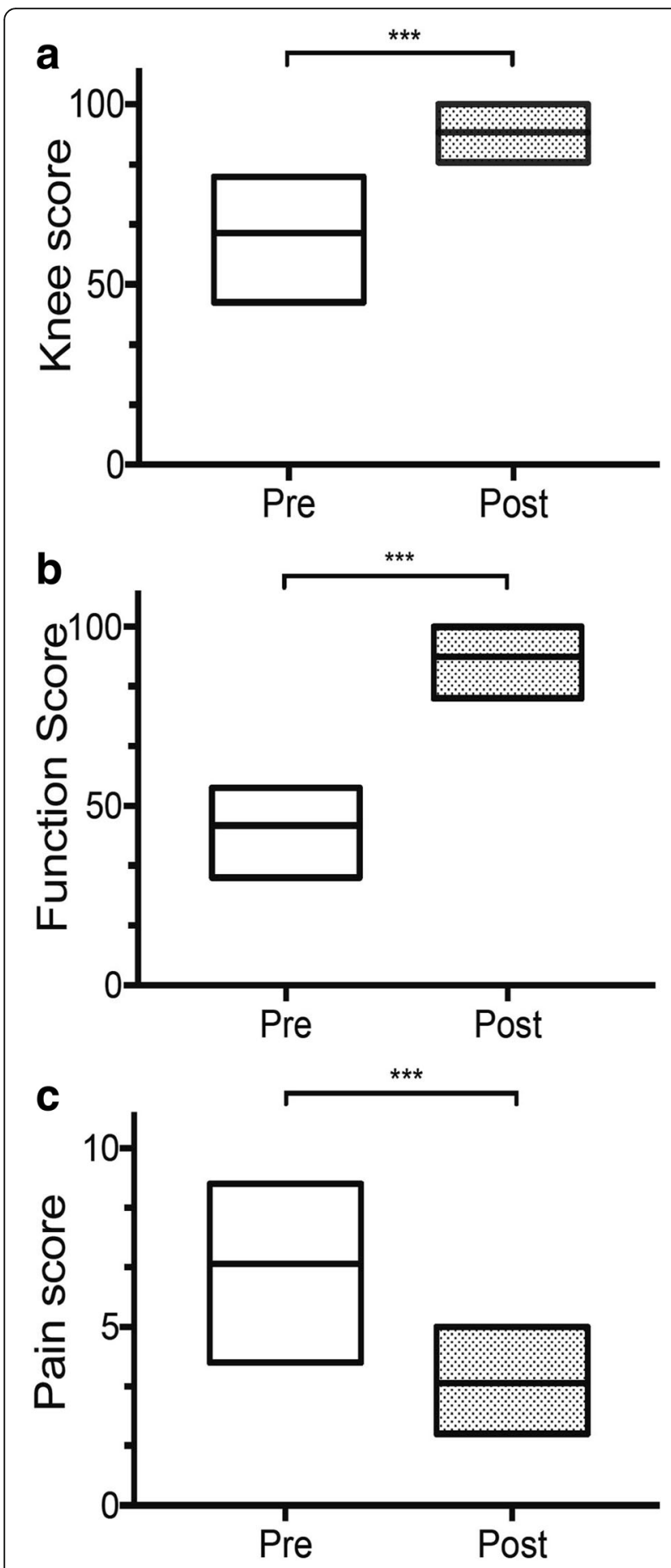

Fig. $3 \mathrm{BMC}$ treatment significantly improved both clinical and functional outcome of early stage OK-SCD patients $(\mathbf{a}, \mathbf{b})$ Preoperative and postoperative changes of Knee and functional score for patients grouped over the entire postoperative period. Floating bar represent max and min range of variation, with line at mean score. c Pain level was evaluated using the Visual Analog Scale. Most of the patients with pain preoperative showed a significant decrease in Pain Scoring ${ }^{*} P<$ $0.05,{ }^{* *} P<0.01,{ }^{* * *} P<0.005$, ${ }^{* * *} P<0.001$ versus preoperative score values (paired t-test) satisfied with the surgical outcome, three $(13 \%)$ were moderately satisfied. The mean NRS satisfaction score obtained was 9.2 at the most recent follow-up.

The total amount of BMC-nucleated cell ranged from 10 to $37 \times 10^{6} \mathrm{cell} / \mathrm{ml}$ (range: $4.5-16.7 \times 10^{8}$ nucleated cell/patient), including $<1.2 \% \mathrm{CD} 34+\mathrm{CD} 45^{\mathrm{dim}}$ positive cells, which are precursors of hematopoietic cells, and 2.1 $+/-1.4 \times 10^{4}$ cells of CFU-F as an indicator of mesenchymal stromal cell activity. These results show that up to 19 . $9 \times 10^{6} \mathrm{CD} 34+\mathrm{CD} 45^{\mathrm{dim}}$ progenitor cells were injected through and distributed into the ostenecrotic zones.

In contrast to the improved clinical outcome, radiographic signs did not change appreciably after BMC implantation. We could not perceive any sign of subchondral fracture or collapse of the femoral condyles or the tibial plateau at the follow-up times after intervention. At the latest radiographic evaluation, any significant subchondral bone changes of radiographic signs, including presence of crescent sign, increased thickness, density, and irregularity were noted. Postoperative MRI scans demonstrated no subchondral bone erosion or fracture, normal contour of the epiphyseal head and preservation of the joint space. Most lesions that appeared stable on MRI were clinically also stable or improved. These results indicate that the joint space was preserved and the subchondral bone was stable after BMC implantation during follow-up period. Figs. 5 and 6 shows representative cases from our series.

\section{Discussion}

The most important finding of the present study is that early stages of osteonecrosis of the knee in SCD patients achieved clinically meaningful and significant improvement after the implantation of BMC, compared to the preoperative situation. The results also demonstrated that BMC could be safely delivered in a concentrated manner to osteonecrotic lesions of the knee and no radiographic evidence of subchondral collapse at midterm follow-up (average: 27.3 months) in SCD patients.

Osteonecrosis of the knee in sickle cell disease is most commonly seen in patients who are younger than 45 years of age, with typical bilateral knee involvement. The medial and lateral femoral condyles are relatively frequent sites for its occurrence [6, 7]. As with osteonecrotic hip in sickle cell disease, variable mechanisms may be implicated in the knee, including interruption of the vascular blood supply to the subchondral bone. If not treated, early stages of OK-SCD have a high likelihood of progression to symptomatic disease and subchondral collapse, as demonstrated for hip, shoulder and ankle [2, 23, 24]. In these situations, conservative treatment is generally not successful, leading to secondary arthritis and total joint replacement in approximately $80 \%$ of cases after $2-5$ years in SCD patients $[2,13]$. 

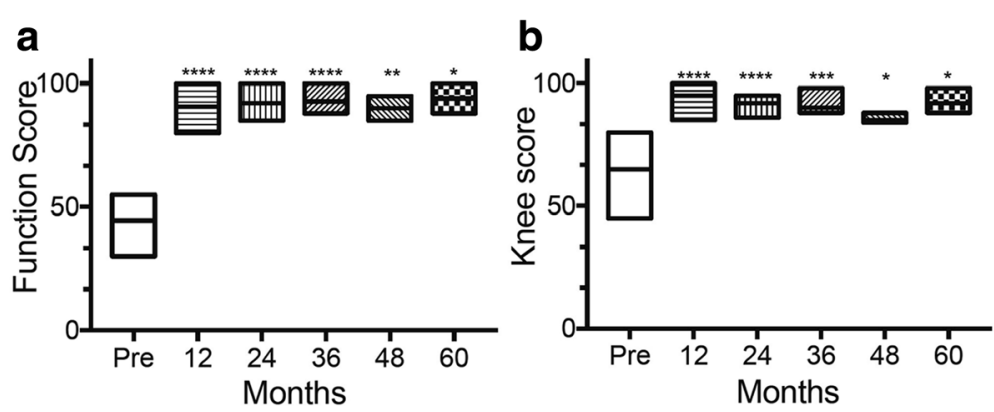

Fig. 4 Functional and clinical improvement over time after BMC implantation. a, b Function score (a) and Knee score (b) evaluation preoperatively and at the time of follow-up showed increased and sustained clinical improvement over time. ${ }^{*} P<0.05,{ }^{* *} P<0.01,{ }^{* * *} P<0.005$, ${ }^{* * * * P}<0.001$ versus preoperative score values (paired t-test)

Joint preservation therapy is the immediate goal of treatment considering the prevalence of OK-SCD among young adult patients in our series. Instead, joint replacement is a controversial option considering the risk and reduced durability of total knee arthroplasty in SCD patients. Recently, Perfetti et al. [4] have shown that sickle cell disease patients admitted for total knee arthroplasty have a $137 \%$ higher risk for perioperative complication than that of non-SCD patients. Moreover, joint replacement was associated with several complications in SCD patients: intra-operative bleeding, infections, and loosening or early loss of the prosthesis [25]. For a small and preliminary study as ours, in which the main focus was

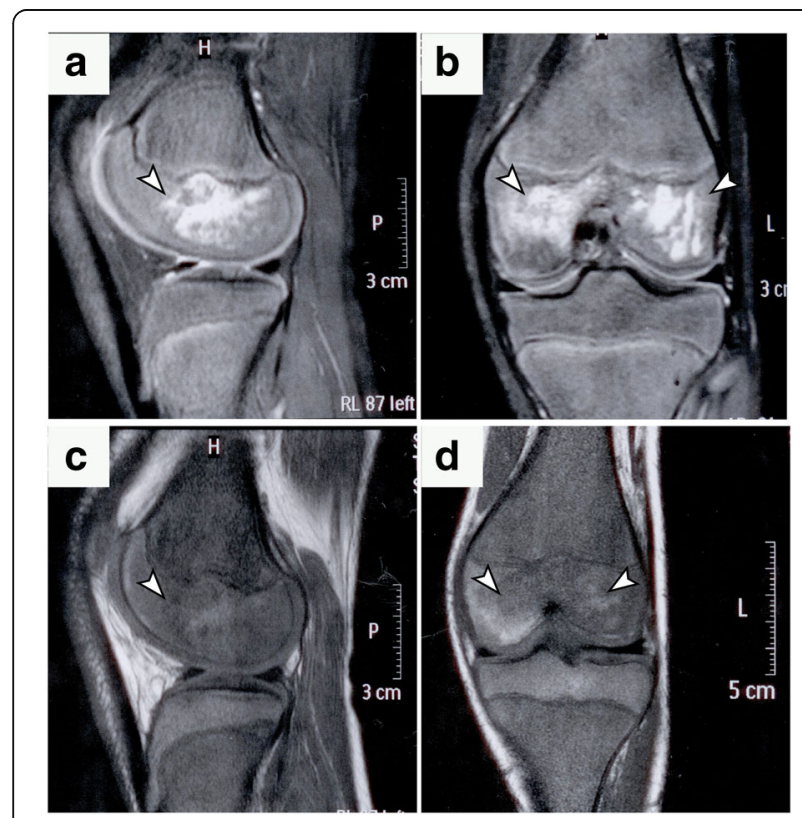

Fig. 5 MR imaging after successfully treatment with BMC. a - c MR imaging of the 16-years-old boy before $(\mathbf{a}, \mathbf{b})$ and after surgery $(\mathbf{c}, \mathbf{d}$, 12 months postoperatively). PD-weighted $(\mathbf{a}, \mathbf{b})$ and T1-weighted (c, d) sequences demonstrate no subchondral bone erosion or fracture, normal contour of the epiphyseal head and preservation of the joint space. Proton density-weighted $(\mathbf{a}, \mathbf{b})$ sequences demonstrate mostly hematopoietic marrow without cystic or fibrotic lesion safety and feasibility, the results confirmed that our knee joint-preserving procedure was promising and had a limited rate of procedure-associated adverse effects. Therefore, we suggest that BMC implantation might be a valuable therapeutic joint preserving option for osteonecrosis of the knee in SCD patients.

Conventional treatments are unable to reverse or halt early stage osteonecrosis of the knee $[26,27]$ and its

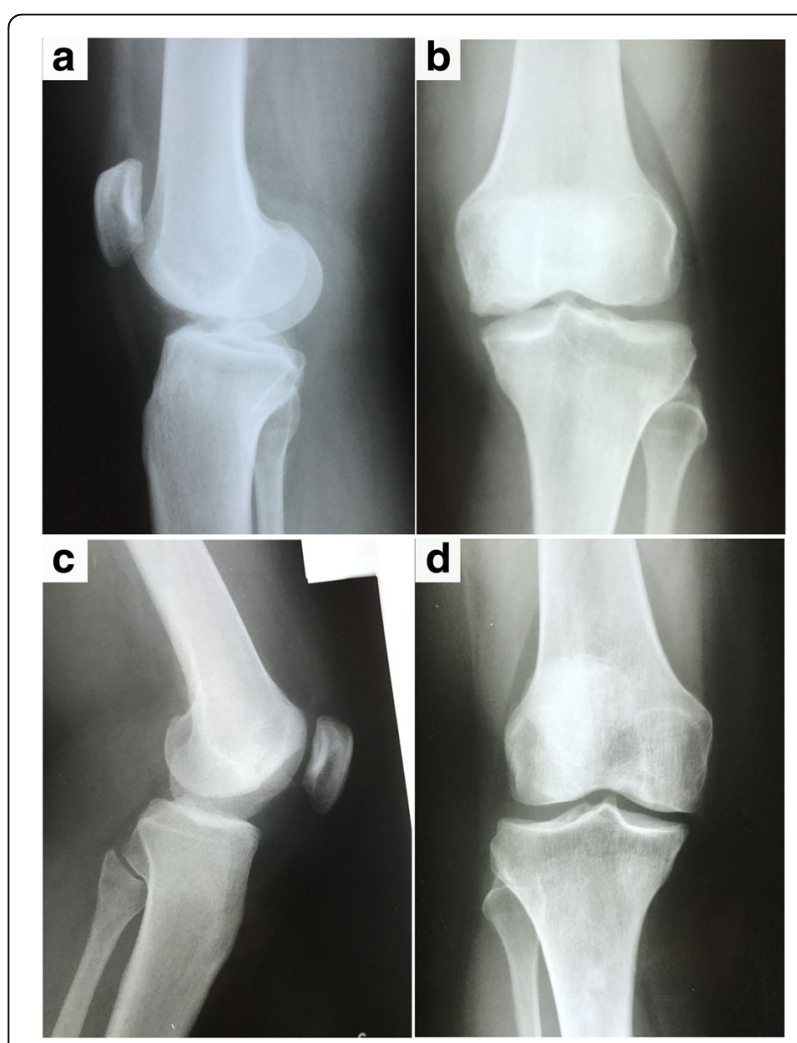

Fig. 6 Radiographic imaging after successfully treatment with BMC. a, $\mathbf{b}$ Radiographs of the patient displayed on Fig. 1, 36 months postoperatively showing joint preservation and no subchondral bone fracture; (c, d) Radiographs of the patient displayed on Fig. 2, 60 months postoperatively. The joint space was preserved and the patient was asymptomatic ate final follow-up 
efficacy remains controversial for SCD patients [8, 9]. MRIs and morphological analysis have shown that no significant repair process in the osteonecrotic lesion could be achieved with core decompression alone [14], calling for additional alternative treatment options, usually with some form of bone grafting. In our series, we included SCD patients with OK in early pre-collapse stages, since its recognition is important for the longterm result of this procedure $[11,12]$.

Here, we treat osteonecrosis by implantation of autologous progenitor stem cells into the necrotic lesion. In sickle cell disease, implantation of BMC has been described for over twenty years with successful results for patients suffering with early stage osteonecrosis of the humeral and femoral head. [13]. This procedure has been used in the senior author's practice for the past ten years for osteonecrosis of the femoral head, and the same technique has been transferred to the knee joint in sickle cell disease patients. The percutaneous minimally invasive technique in our study uses small-diameter marrow-needle as a modification of core decompression, proper patient immobilization and knee positioning, with minimal morbidity being associated with the procedure. Furthermore, surgery was performed carefully, with minimal trauma to avoid unexpected drilling through the articular cartilage surface or supracondylar femur fracture in OK-SCD patients.

Autologous concentrated bone marrow-based approaches for knee osteonecrosis have been limited to case reports or to osteonecrosis associated with other risk factors rather then sickle cell disease [27]. Recently, Goodman et al. [28] have shown that 12 young patients (fourteen knees) with OK associated to corticosteroid and submitted to local debridement before osteoprogenitor cell grafting had excellent pain relief and function, integration of the graft and no radiographic evidence of subchondral collapse at up to 5 years postoperatively. Marulanda et al. [26] reported a series of 61 knees (38 patients) with OK treated by a technique using multiple small percutaneous $3 \mathrm{~mm}$ drillings. A total of 56 (92\%) had a successful clinical outcome, with 5 (8\%) knees progressing to further surgery. Buda and colleagues [29] evaluated the midterm (average follow-up: 29 months) results of 30 patients with post-traumatic osteochondral lesions of the knee treated predominantly by arthroscopic transplantation of concentrated bone-marrow aspirate with a scaffold into the lesion site. They reported good to excellent results in all the patients based on the IKDC and KOOS scores, and growth of bone and cartilage, nearly complete defect filling and satisfactory integration of the graft at follow-up in $80 \%$ of cases [29]. Gobbi et al. [30] reported a long-term and sustained benefit of concentrated bone-marrow aspirate compared to microfracture for the treatment of osteochondral lesions of the knees. Zellner et al. [31] described promising clinical and radiological results, achieving successful bone regeneration of large and deep osteochondral defects of the knee joint after the treatment with concentrated bone-marrow aspirate combined with bone augmentation. In our study, arthroplasty was avoided in all the patients during the follow-up period. There was also significant improvement in the KSS, KFS and NRS pain score at the time of the latest follow up. Only 4 knees (out of 33) had persistent painful symptoms after treatment, which required pharmacological management. These outcomes are promising in that knee osteonecrosis can be safely and effectively treated with BMC implantation. Although these initial results seem quite encouraging, longer-term follow up is clearly needed.

Consistent with the previously published results from our group and others, significant improvement of pain was observed in knee joints following injection with BMC [12, 32]. Pain in the knee is often referred in patients with hip disorders [33]. However, patients were selected based on the knee pain, and the distribution of knee pain was not significantly different when patients had previous diagnosis of hip osteonecrosis. We suggest that SCD patients with knee osteonecrosis often present with pain because the main lesion is on the knee, especially in the medial femoral condyle (load transmitting area). Treatment of knee osteonecrosis with BMC showed only local improvement and no effect on the other joints, which is consistent with previous reports [30-32].

Cell therapy efficacy for osteonecrotic lesions depends on the quantity of implanted viable BM nucleated cells and stem cells progenitors [13]. Hematopoietic/endothelial progenitors $\left(\mathrm{CD} 34 \mathrm{CD} 45^{\text {low }}\right)$, mesenchymal stromal cells (CFU-F) and nucleated cell into the osteonecrotic lesion may help by replenishing damaged joint structures and providing modulation of the immune response, thus alleviating the symptoms and progression of the disease [13, 14, 30]. However, the correlation between BMC implantation and clinical success is in open investigation. Prior studies investigating a relationship between the cellular dose contained within the bone marrow concentrate and efficacy of the treatment for knee osteoarthritis have shown that patients receiving a higher concentration of cells $\left(<10^{8}\right.$ nucleated cell/patient) reported a better pain outcome in comparison with the lower dose group [32]. In our study, the cellular doses administered were adequately high above the BMC-nucleated cell indicated. Moreover, the frequency of hematopoietic/endothelial progenitors (CD34CD45 ${ }^{\text {low }}$ ) and mesenchymal stromal cells (CFU-F) were consistent with those in the literature, and the number of CFU-F that was injected was in accordance with previous clinical studies (between 25,000 and 
200,000 CFU-Fs) [13, 14]. Therefore, despite a low number of sample sizes tested, these results suggest that there is no deficiency in the quantity of grafted SCD patient's marrow stromal cell populations.

We are conscious that our experimental design has several limitations. The presented data collection is not a controlled study. Sickle cell disease is a systemic lifethreatening hemoglobinopathy associated with several comorbidities, and there is no current standard treatment for osteonecrosis in these patients. Also, the inclusion of a control group (placebo group) was not in accordance with ethical recommendations of the national authorities that have analyzed and provided the financial support for this study. Quite clearly, prospective randomized studies including a comparison with an active control group would be nevertheless desirable, in order to determine more comprehensively the efficacy of the treatment described in this study.

Our study has several others limitations: 1) The number of patients is small and the follow-up short to intermediate term; 2) We selected only patients who had associated osteonecrosis of the hip. Because there may be patients with knee osteonecrosis who do not have hip osteonecrosis, this study population might not represent all sickle cell patients with osteonecrosis of the knee; 3 ) We cannot be sure that implanted BMCs remained at the site of implantation during the follow up period; 4) Another limitation is consequent to the fact that only a few patients underwent MRI during the follow-up because of the costs associated with imaging asymptomatic patients with sickle cell disease. Monitoring bone formation in the necrotic area or examine how BMC implantation may have affected outcomes should be incorporated in future studies.

\section{Conclusion}

Despite these limitations, implantation of $\mathrm{BMC}$ in young sickle cell disease patients with secondary osteonecrosis of the knee was relatively simple, promoted pain relief and functional improvement at midterm follow-up. This technique does not preclude further reconstructive operations, if necessary. This prospective pilot study suggest that the treatment strategy of BMC is a promising strategy and may be useful to treat early stage knee osteonecrosis in sickle cell disease patients without subchondral bone collapse and large degenerative changes of the cartilage.

\section{Abbreviations}

BMC: Bone marrow mononuclear cells; CFU: Colony-forming units; EPC: Endothelial progenitors cell; HbS: Hemoglobin S; KSS: Knee Society Score; MRI: Magnetic Resonance Imaging; MSC: Bone marrow-derived mesenchymal stromal cell; OK: Osteonecrosis of the knee; SCD: Sickle cell disease

\section{Funding}

This work was supported by the Brazilian National Research Council (CNPq) and the Research Support Foundation of the State of Bahia (FAPESB).

\section{Availability of data and materials}

All data are fully available without restriction. Data are available from the internal database of Prof. Edgar Santos Hospital Complex, Federal University of Bahia, Bahia, Brazil, upon Ethics Committee approval for researchers who meet the criteria for access to confidential data.

\section{Authors' contributions}

GD, TBF and DAR were the surgeons who performed surgeries in this study. TBF and DAR assessed most of the clinical outcomes. BAF assessed most of the radiological outcomes. GD, RM and VF were responsible for conception, design, critical revision and data analysis. VF and PBD assisted the surgery in this study and carried out the follow-up symptom assessment and data collection. RM drafted part of the manuscript. VF coordinated and made a major contribution to writing the manuscript. All authors read and approved the final manuscript.

\section{Ethics approval and consent to participate}

The Committee of Ethics in Research of the Climério de Oliveira Maternity and the National Committee of Ethics in Research (CONEP) approved the protocol of the present study under the authorization of the Ministry of Public Health of Brazil [registration number 11738, SIPAR/MS: 25000.039812/ 2005-99]. NIH trial registration: ClinicalTrials.gov NCT02448121. Retrospectively registered. Written informed consent was obtained from every patient before enrollment in the study.

\section{Competing interests}

The authors declare that they have no competing interests.

\section{Publisher's Note}

Springer Nature remains neutral with regard to jurisdictional claims in published maps and institutional affiliations.

\section{Author details}

${ }^{1}$ Prof. Edgar Santos Hospital Complex, Federal University of Bahia, R. Doutor Augusto Viana, s/n - Canela, Salvador, BA 40110-060, Brazil. ${ }^{2}$ Health Science Institute, Federal University of Bahia, Av. Reitor Miguel Calmon, s/n, Vale do Canela, Salvador, BA 40110-100, Brazil.

Received: 17 November 2017 Accepted: 30 April 2018

Published online: 22 May 2018

\section{References}

1. Aguilar C, Vichinsky E, Neumayr L. Bone and joint disease in sickle cell disease. Hematol Oncol Clin North Am. 2005;19:929-41.

2. Hernigou P, Habibi A, Bachir D, Galacteros F. The natural history of asymptomatic osteonecrosis of the femoral head in adults with sickle cell disease. J Bone Joint Surg Am. 2006;88:2565-72.

3. Yildizgoren MT, Helvaci MR, Ustun N, Osmanoglu K, Turhanoglu AD. Ultrasonographic assessment of the distal femoral cartilage thickness in patients with homozygous sickle cell disease. Cartilage. 2016;7:217-2.

4. Perfetti DC, Boylan MR, Naziri Q, Khanuja HS, Urban WP. Does sickle cell disease increase risk of adverse outcomes following total hip and knee arthroplasty? A nationwide database study. J Arthroplast. 2015;30:547-51.

5. Sun W, Shi Z, Gao F, Wang B, Li Z. The pathogenesis of multifocal osteonecrosis. Sci Rep. 2016;6:29576-82

6. Flouzat-Lachaniete CH, Roussignol X, Poignard A, Mukasa MM, Manicom O, Hernigou P. Multifocal joint osteonecrosis in sickle cell disease. Open Orthop J. 2009;3:32-5.

7. Karim AR, Cherian JJ, Jauregui JJ, Pierce T, Mont MA. Osteonecrosis of the knee: review. Ann Transl Med. 2015;3:6-17.

8. Neumayr LD, Aguilar C, Earles AN, Jergesen HE, Haberkern CM, Kammen BF, et al. Physical therapy alone compared with core decompression and physical therapy for femoral head osteonecrosis in sickle cell disease. Results of a multicenter study at a mean of three years after treatment. J Bone Joint Surg Am. 2006;88:2573-82.

9. Al Omran A. Multiple drilling compared with standard core decompression for avascular necrosis of the femoral head in sickle cell disease patients. Arch Orthop Trauma Surg. 2013;133:609-13. 
10. Sadile F, Bernasconi A, Russo S, Maffulli N. Core decompression versus other joint preserving treatments for osteonecrosis of the femoral head: a metaanalysis. Br Med Bull. 2016;118:33-49.

11. Hernigou P, Daltro G, Filippini P, Mukasa MM, Manicom O. Percutaneous implantation of autologous bone marrow osteoprogenitor cells as treatment of bone avascular necrosis related to sickle cell disease. Open Orthop J. 2008;2:62-5.

12. Daltro GC, Fortuna V, de Souza ES, Salles MM, Carreira AC, Meyer R, et al. Efficacy of autologous stem cell-based therapy for osteonecrosis of the femoral head in sickle cell disease: a five-year follow-up study. Stem Cell Res Ther. 2015;6:110-28.

13. Hernigou P, Trousselier M, Roubineau F, Bouthors C, Chevallier N, Rouard H, et al. Stem cell therapy for the treatment of hip osteonecrosis: a 30-year review of progress. Clin Orthop Surg. 2016;8:1-8.

14. Piuzzi NS, Chahla J, Schrock JB, LaPrade RF, Pascual-Garrido C, Mont MA, et al. Evidence for the use of cell-based therapy for the treatment of osteonecrosis of the femoral head: a systematic review of the literature. J Arthroplast. 2017;32:1698-08.

15. Lebouvier A, Poignard A, Coquelin-Salsac L, Léotot J, Homma Y, Jullien N, et al. Autologous bone marrow stromal cells are promising candidates for cell therapy approaches to treat bone degeneration in sickle cell disease. Stem Cell Res. 2015;15:584-94.

16. Ficat RP. Idiopathic bone necrosis of the femoral head. Early diagnosis and treatment. J Bone Joint Surg Br. 1985;67:3-9.

17. Mont MA, Tomek IM, Hungerford DS. Core decompression for avascular necrosis of the distal femur: long term follow-up. Clin Orthop Relat Res. 1997;334:124-30.

18. Mont MA, Baumgarten KM, Rifai A, et al. Atraumatic osteonecrosis of the knee. J Bone Joint Surg Am. 2000;82:1279-90.

19. Lecouvet FE, van de Berg BC, Maldague BE, Lebon CJ, Jamart J, Saleh M, et al. Early irreversible osteonecrosis versus transient lesions of the femoral condyles: prognostic value of subchondral bone and marrow changes on MR imaging. Am J Roentgenol. 1998;170:71-7.

20. Asif $\mathrm{S}$, Choon DS. Midterm results of cemented press fit condylar sigma total knee arthroplasty system. J Orthop Surg (Hong Kong). 2005 Dec;13(3):280-4.

21. Thomsen MG, Latifi R, Kallemose T, Barfod KW, Husted H, Troelsen A. Good validity and reliability of the forgotten joint score in evaluating the outcome of total knee arthroplasty. Acta Orthop. 2016;87:280-5.

22. Hawker GA, Mian S, Kendzerska T, French M. Measures of adult pain: visual analog scale for pain (VAS pain), numeric rating scale for pain (NRS pain), McGill pain questionnaire (MPQ), short-form McGill pain questionnaire (SFMPQ), chronic pain grade scale (CPGS), short Form-36 bodily pain scale (SF36 BPS), and measure of intermittent and constant osteoarthritis pain (ICOAP). Arthritis Care Res. 2011;63(Suppl 11):S240-52.

23. Hernigou P, Flouzat-Lachaniette $\mathrm{CH}$, Daltro G, Galacteros F. Talar osteonecrosis related to adult sickle cell disease: natural evolution from early to late stage. J Bone Joint Surg Am. 2016;98:1113-21.

24. Poignard A, Flouzat-Lachaniette CH, Amzallag J, Galacteros F, Hernigou P. The natural progression of symptomatic humeral head osteonecrosis in adults with sickle cell disease. J Bone Joint Surg Am. 2012;94:156-62.

25. Kamble S, Telen MJ, Dinan MA, Grussemeyer CA, Reed SD. Costs and length of stay for patients with and without sickle cell disease after hysterectomy, appendectomy, or knee replacement. Am J Hematol. 2010;85:79-81.

26. Marulanda G, Seyler TM, Sheikh NH, Mont MA. Percutaneous drilling for the treatment of secondary osteonecrosis of the knee. J Bone Joint Surg Br. 2006;88:740-6

27. Lieberman JR, Varthi AG, Polkowski GG 2nd. Osteonecrosis of the knee which joint preservation procedures work? J Arthroplast. 2014;29:52-6.

28. Goodman SB, Hwang KL. Treatment of secondary osteonecrosis of the knee with local debridement and Osteoprogenitor cell grafting. J Arthroplast. 2015;30:1892-6.

29. Buda R, Vannini F, Cavallo M, Baldassarri M, Luciani D, Mazzotti A, Pungetti C, Olivieri A, Giannini S. One-step arthroscopic technique for the treatment of osteochondral lesions of the knee with bone-marrow-derived cells: three years results. Musculoskelet Surg. 2013;97:145-51.

30. Gobbi A, Whyte GP. One-stage cartilage repair using a hyaluronic acidbased scaffold with activated bone marrow-derived mesenchymal stem cells compared with microfracture five-year follow-up. Am J Sports Med. 2016;44:2846-54

31. Zellner J, Grechenig S, Pfeifer CG, Krutsch W, Koch M, Welsch G, Scherl M, Seitz J, Zeman F, Nerlich M, Angele P. Clinical and radiological regeneration of large and deep osteochondral defects of the knee by bone augmentation combined with matrix-guided autologous chondrocyte transplantation. Am J Sports Med. 2017;45:3069-80.

32. Centeno CJ, Al-Sayegh H, Bashir J, Goodyear S, Freeman MD. A dose response analysis of a specific bone marrow concentrate treatment protocol for knee osteoarthritis. BMC Musculoskelet Disord. 2015;16:258.

33. Nakamura J, Konno K, Orita S, Hagiwara S, Shigemura T, Nakajima T, Suzuki T, Akagi R, Ohtori S. Distribution of hip pain in patients with idiopathic osteonecrosis of the femoral head. Mod Rheumatol. 2017:27:503-7.

\section{Ready to submit your research? Choose BMC and benefit from:}

- fast, convenient online submission

- thorough peer review by experienced researchers in your field

- rapid publication on acceptance

- support for research data, including large and complex data types

- gold Open Access which fosters wider collaboration and increased citations

- maximum visibility for your research: over $100 \mathrm{M}$ website views per year

At BMC, research is always in progress.

Learn more biomedcentral.com/submissions 